Portland State University

PDXScholar

TREC Final Reports

Transportation Research and Education Center

(TREC)

3-2021

\title{
Rethinking Streets for Physical Distancing
}

\author{
Marc Schlossberg \\ University of Oregon \\ Rebecca Lewis \\ University of Oregon \\ Aliza Whalen \\ University of Oregon \\ Clare Haley \\ University of Oregon \\ Danielle Lewis \\ University of Oregon
}

See next page for additional authors

Follow this and additional works at: https://pdxscholar.library.pdx.edu/trec_reports

Part of the Transportation Commons, Urban Studies Commons, and the Urban Studies and Planning Commons

Let us know how access to this document benefits you.

\section{Recommended Citation}

Schlossberg, Marc, Rebecca Lewis, Aliza Whalen, Clare Haley, Danielle Lewis, Natalie Kataoka, and John Larson-Friend. Rethinking Streets for Physical Distancing. NITC-RR- 1447. Portland, OR: Transportation Research and Education Center (TREC), 2021.https://dx.doi.org/10.15760/trec.257

This Report is brought to you for free and open access. It has been accepted for inclusion in TREC Final Reports by an authorized administrator of PDXScholar. Please contact us if we can make this document more accessible: pdxscholar@pdx.edu. 
Authors

Marc Schlossberg, Rebecca Lewis, Aliza Whalen, Clare Haley, Danielle Lewis, Natalie Kataoka, and John Larson-Friend 

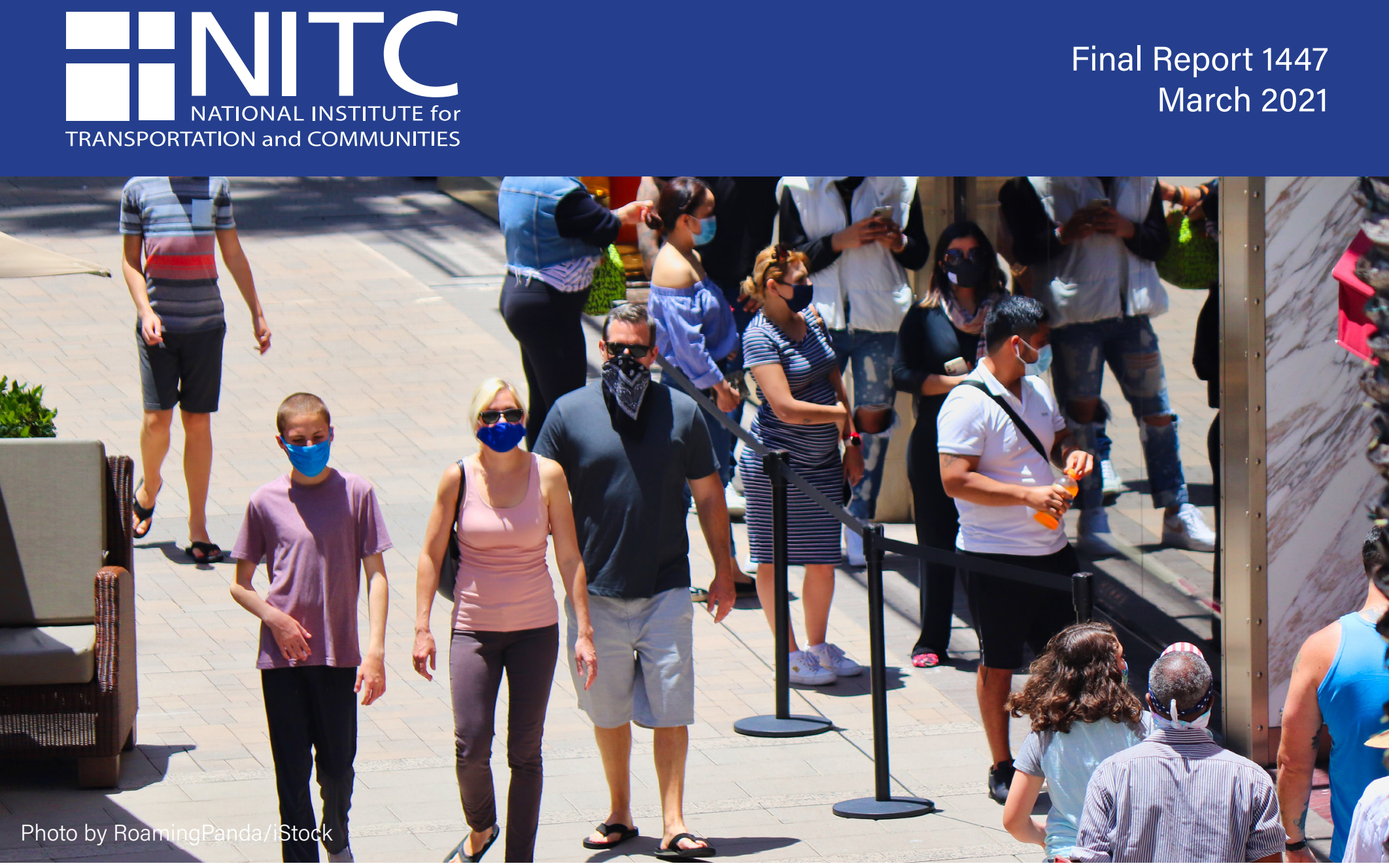

\section{Rethinking Streets for Physical Distancing}

Marc Schlossberg, Ph.D.

Rebecca Lewis, Ph.D.

Aliza Whalen, Clare Haley, Danielle Lewis, Natalie Kataoka and John Larson-Friend

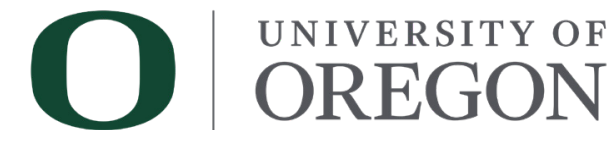




\title{
RETHINKING STREETS FOR PHYSICAL DISTANCING
}

\author{
Final Report
}

NITC-RR-1447

\author{
by \\ Marc Schlossberg \\ Rebecca Lewis \\ Aliza Whalen \\ Clare Haley \\ Danielle Lewis \\ Natalie Kataoka \\ John Larson-Friend \\ University of Oregon
}

for

National Institute for Transportation and Communities (NITC)

P.O. Box 751

Portland, OR 97207

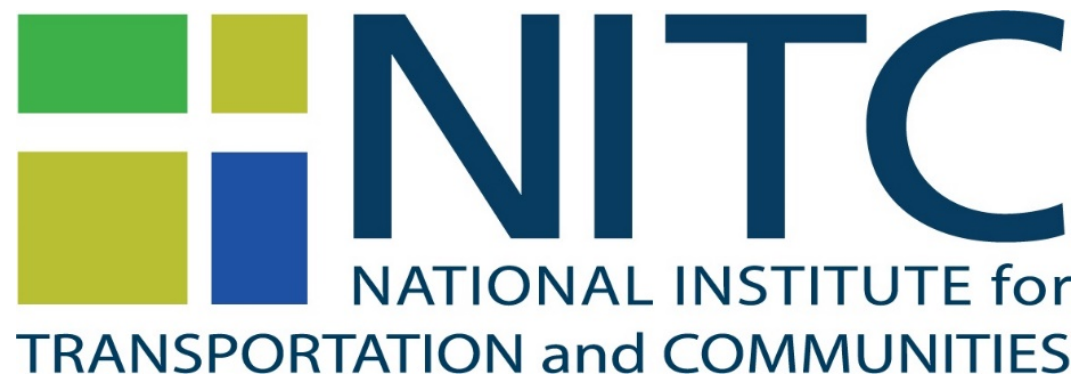

March 2021 


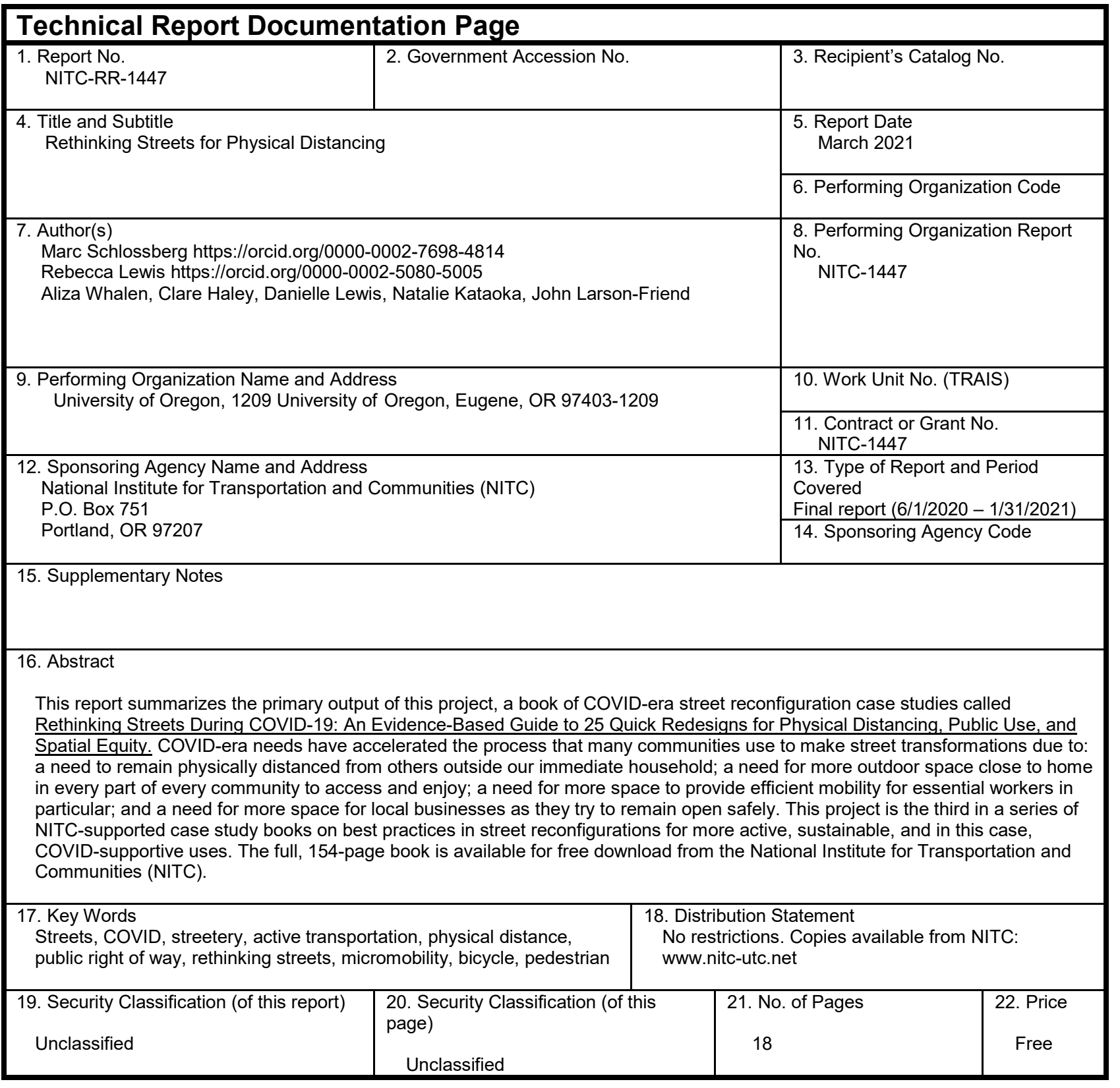




\section{ACKNOWLEDGEMENTS}

This project was funded by the National Institute for Transportation and Communities (NITC; grant number 1447), a U.S. DOT University Transportation Center.

We would like to acknowledge Dave Amos (Assistant Professor in City and Regional Planning, Cal Poly San Luis Obispo), John Rowell (Associate Professor, Architecture, University of Oregon), and Roger Lindgren (Professor, Civil Engineering, Oregon Institute of Technology) for the timely guidance and critical evaluation along the way. All were core authors of previous Rethinking Streets volumes and we all benefitted from their contributions on this version.

We also want to acknowledge the excellent work by Dr. Tabitha Combs at the University of North Carolina, NACTO, and PBIC in quickly creating databases of municipal street changes that formed the starting point for our case study selection. While PBIC's database eventually used and built on Dr. Combs' initial work, it was her initial initiative in documenting city efforts that inspired us to undertake this project and we would like to recognize her specifically..

While already acknowledged as co-authors, we would like to especially call out the extraordinary work of the student team on this project: graduate students in City and Regional Planning Aliza Whalen, Clare Haley, and John Larson-Friend; undergraduate student in Art and Technology Danielle Lewis; and undergraduate student in Environmental Science and Planning, Public Policy and Management (PPPM) Natalie Kataoka. The previous two Rethinking Streets editions took 15-18 months to produce and this version was finished in under five, and much of that accomplishment was due to these amazing students.

\section{DISCLAIMER}

The contents of this report reflect the views of the authors, who are solely responsible for the facts and the accuracy of the material and information presented herein. This document is disseminated under the sponsorship of the U.S. Department of Transportation University Transportation Centers Program in the interest of information exchange. The U.S. Government assumes no liability for the contents or use thereof. The contents do not necessarily reflect the official views of the U.S. Government. This report does not constitute a standard, specification, or regulation.

\section{RECOMMENDED CITATION}

Schlossberg, Marc, Rebecca Lewis, Aliza Whalen, Clare Haley, Danielle Lewis, Natalie Kataoka, and John Larson-Friend. Rethinking Streets for Physical Distancing. NITC-RR1447. Portland, OR: Transportation Research and Education Center (TREC), 2021. 


\section{TABLE OF CONTENTS}

EXECUTIVE SUMMARY

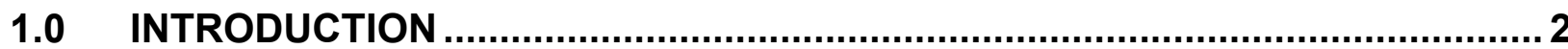

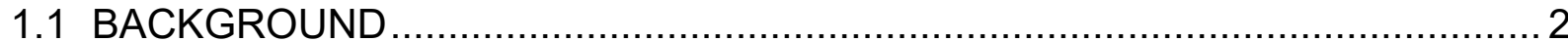

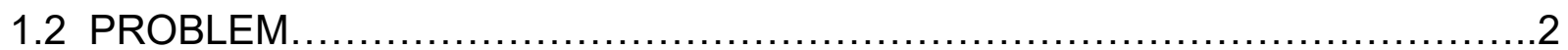

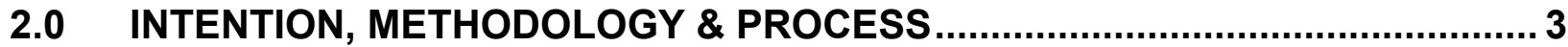

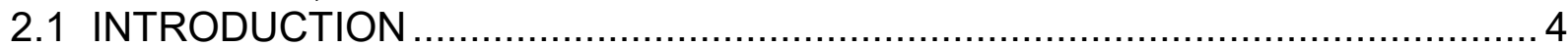

2.2 METHOD FOR DEVELOPING GUIDEBOOK CONTENT ............................ 4

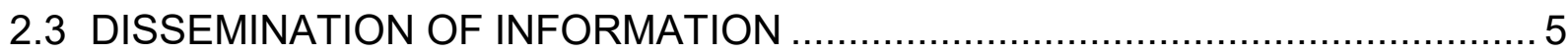

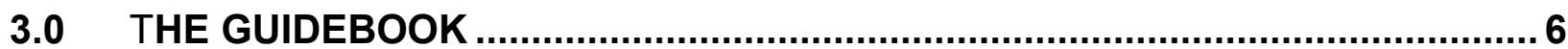

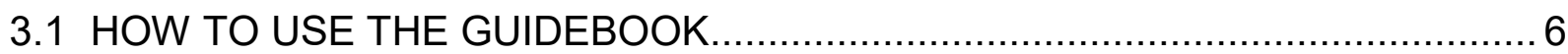

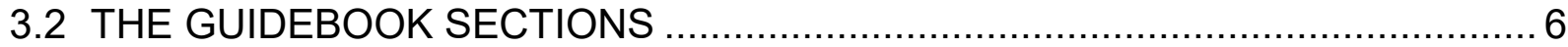

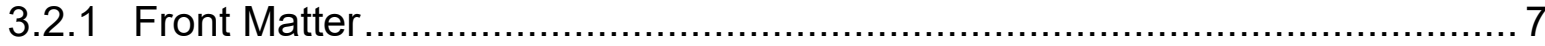

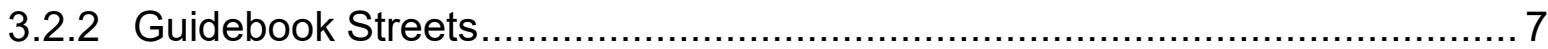

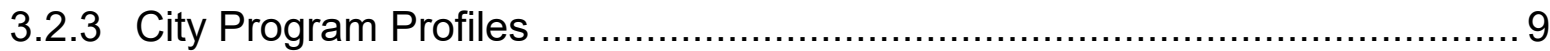

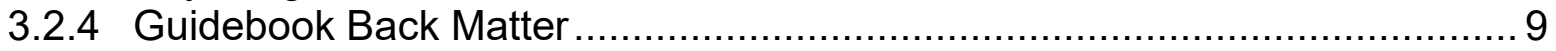

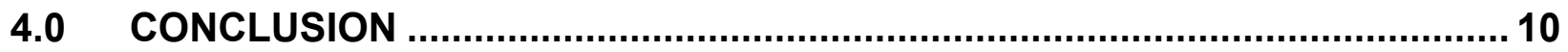

\section{LIST OF FIGURES}

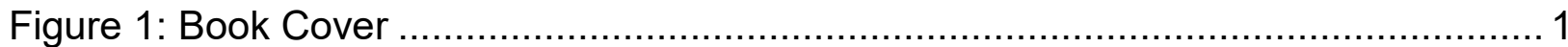

Figure 2: Example of Street Cross Section Changes and the Accompanying Information

Bar

Figure 3: Sample Pages "How to Use This Guide".................................................... 7

Figure 4: Sample Four-Page Case Study Spread .............................................. 8

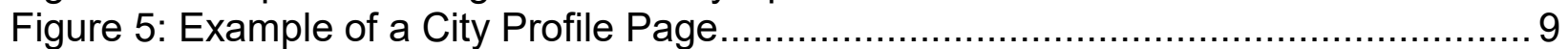

Figure 6: Sample Page of Case Study Citations. ................................................ 10 


\section{EXECUTIVE SUMMARY}

This project is the third in a series of NITC-supported projects to investigate and document best practices in street reconfigurations for more active, sustainable, and in this case, COVID-supportive uses.

Reallocating space on streets to accommodate new uses - particularly for walking, biking, and being - is not new. However, COVID-era needs have accelerated the process that many communities use to make such street transitions. A few overlapping phenomena quickly became clear during the early days of COVID: a need to remain physically distanced from others outside our immediate household; a need for more outdoor space close to home in every part of every community to access and enjoy; a need for more space to provide efficient mobility for essential workers in particular; and a need for more space for local businesses as they try to remain open safely.

This report summarizes the process and rationale for developing an analysis of COVIDbased street reconfigurations. A parallel output from the project, in addition to this report, was a simultaneous creation of a visually accessible, fleshed-out book of COVID-era street reconfiguration case studies called Rethinking Streets During COVID19: An Evidence-Based Guide to 25 Quick Redesigns for Physical Distancing, Public Use, and Spatial Equity. That output captures and communicates to a broad array of professional and lay stakeholders some of the quick changes cities across the United States made to city streets in response to societal needs during COVID so that their communities may be better able to respond to similar goals with this evidence-based resource as a guide.

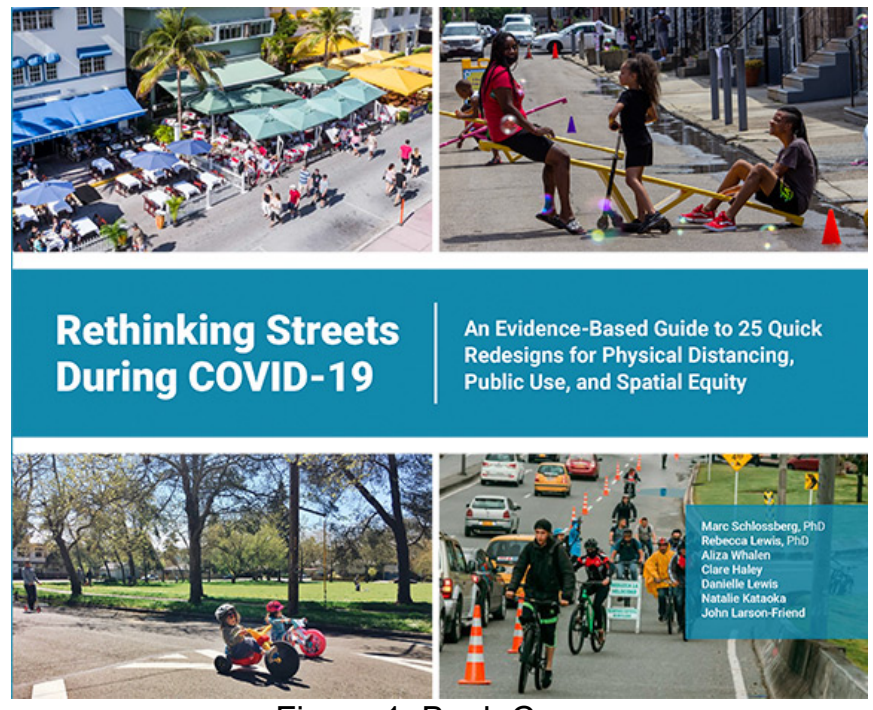

Figure 1: Book Cover 


\subsection{INTRODUCTION}

\subsection{BACKGROUND}

Redesigning cities and streets to make them safer, more comfortable, and ultimately more used by people on bikes or scooters has been undergoing tremendous growth in cities across the country as well as in transportation research, yet we have witnessed a significant acceleration in the reuse of city streets for non-automobile use during the COVID-19 pandemic, especially during the early months.

This was done because transit and ride hailing use plummeted; employment came to a halt, resulting in dramatic declines of personal car use; and social distancing and shelter-at-home orders created a need to access public space in new ways and the street is usually the largest source of public space in any city. At the same time, bicycle purchasing significantly increased and more people and families began experiencing their streets by foot or bike in completely new ways. As some communities began relaxing their social distancing measures, many streets in restaurant areas "opened up" for more restaurant seating in order to increase tables that could not be accommodated within restricted inside spaces.

The purpose of this project was to document the range of ways that cities quickly reconfigured their streets to meet COVID-era demands and to present the cases in ways that additional communities could use as they relook at the use of their streets to meet a wider range of community needs than the conventional view of the street as a public space used primarily for the movement and storage of private automobiles.

\subsection{PROBLEM}

Many overlapping disruptions are pushing a relook at the purpose of our streets and how to get more out of our transportation system than simply maximizing the throughput of privately owned vehicles. Around the world, emissions from transportation are rising while emissions from industrial sources and electricity are falling. -Transportation contributes the largest share of greenhouse gas emissions in the United States (Environmental Protection Agency, 2018) yet most U.S. cities are struggling to move the dial on prioritizing low-carbon, non-car modes of transport, often because it is politically difficult to reconfigure streets away from designs that have been in place for 70 years.

There are several reasons why cities need to rethink their streets as a key strategy to meet climate and other concurrent goals. We know that more of the population wishes to bike, for example, than current street designs allow for (Maaza, et. al 2012; Dill and McNeil 2016). Streets represent one of the most pervasive and universally distributed sets of public space within cities, creating opportunities for more public uses than just 
moving vehicles (Mehta 2013; Gehl 2013). Lowering transportation costs by making non-car modes convenient and direct improves household affordability (Hamidi and Ewing (2015). And then there are also public health (Saelens et. al 2003) and ecological (Ahem 2013) reasons, among others, why cities may want to reconfigure streets to achieve more comprehensive outcomes for their local communities.

Several recent transportation "disruptions" have accelerated many cities' awareness of needed street changes. For example, in 2017, ride hailing trips already grew to over 2.6 billion trips (Schaller, 2018), surpassing local bus ridership by the end of 2018 despite being in existence for under a decade (Howell, et. al., 2020). In recent years, bike share has also grown greatly, particularly with the introduction of dockless systems, rising from 35 to 52 million trips just between 2017 and 2018 (Howell et. al., 2020). And while e-scooters were first introduced only in 2017, they accounted for 84 million trips only one year later (National Association of City Transportation Officials, 2018). And yet, the process of local street change to direct or accommodate these disruptions often remained sluggish and uncertain as cities tried to figure out what would be best for their communities and what would be politically feasible to do with changing street designs.

When COVID-19 appeared, additional changes to city transportation and public space systems were immediately jolted. Coronavirus lockdowns had major impacts on greenhouse gas emissions, traffic volumes, and air quality in cities throughout the world. In April 2020, global daily CO2 emissions had declined an average of 17 percent from 2019 levels, and half of those reductions were due to changes in surface transportation patterns (Le Quéré et al., 2020). In the U.S, transit ridership nationwide decreased by 75 percent (American Public Transit Association, 2020). TNC ridership plummeted; two months into the pandemic, Uber reported an 80 percent decline and Lyft reported a 75 percent decline compared to the year prior (Conger, 2020). In contrast, U.S., bicycle sales doubled from the previous year, and electric bicycle sales were up 85 percent (Goldbaum, 2020).

In addition, as density restrictions on bars and restaurants went into effect, those establishments looked to keep customers through expansion into the public right of way of sidewalks, parking lanes, and street travel lanes. Suddenly, cities needed to act much more quickly about configurations of their streets than their usual process allowed and to do so with little guidance or quick examples from elsewhere to draw on. This project intended to fill that gap for the future by documenting the quick changes cities made during the first nine months of COVID-19, organizing the data about the changes and presenting the information in publicly accessible ways to be used as a guidebook for future changes, whether to meet COVID-era needs or general changing desires about street configuration.

\subsection{INTENTION, METHODOLOGY \& PROCESS}




\subsection{INTRODUCTION}

The objectives of this project were fairly straightforward:

1. To identify existing examples across the United States from a variety of regions and built environment conditions of street reconfigurations completed to address COVID-era needs;

2. To document their existing conditions, including right of way, cross sections, transportation and design elements, project purpose, and intended permanence;

3. To translate this information into a guidebook for professionals (in particular, traffic engineers, transportation planners and urban designers), policymakers, community groups, and citizens to make evidence- and performance-based decisions on redesigns of streets in their communities;

4. To distribute this handbook widely to a range of stakeholder groups; and

5. To build on the highly successful approach and design template of the previous two NITC Rethinking Streets projects.

In addition, the overarching approach to communicating this range of information is to do so in a visually rich, easily accessible and understandable manner that allows all stakeholders to engage with material of importance to them, while also giving each stakeholder access to information that other stakeholders tend to focus on in their decision-making processes. Thus, the project's intention is to create a resource that can both engage a wide variety of community stakeholders in street retrofit decision making and providing each stakeholder an opportunity to understand how others make decisions. As a quick turnaround project, the intention is also to get tangible, practice-oriented knowledge into the hands of professionals who could use it while the pandemic continues to rage on. Thus, this resource is intended for both immediate use, as well as for communities to take the principles found throughout the book and find ways to adapt them for their own contexts to create flexibility in both COVID and non-COVID times.

\subsection{METHOD FOR DEVELOPING GUIDEBOOK CONTENT}

The research team developed the guidebook content in several ways, but primarily relied on three real-time project identification data collection efforts by: Dr. Tabitha Combs at the University of North Carolina, the National Association of City Transportation Officials (NACTO), and the Pedestrian and Bicycle Information Center (PBIC). (Dr. Combs' work eventually fed into and formed the foundation of the PBIC database.) Our team went through these daily updated databases, in addition to scanning popular press and key social media accounts, to find a range of possible street reconfigurations to document.

Possible cases were divided into different types of street treatments and a final set of possible sites were chosen with the goal to represent a range of city types, from different regions of the country, and to highlight efforts that seemed relatively easy, quick, affordable, and effective. 
Using information from any local press stories (more common) about the project and from local government documentation (less common), the team went about telling the story of each case utilizing a similar four-page, visual spread utilized in the previous two Rethinking Streets volumes. Initial street right of way and lane widths were calculated using Google maps and were used for our original street cross-section creations. Each city was also contacted about possible inclusion in the book and we asked for any additional information about the street or program they had to share. When a case study spread was in near completed draft form, we sent the spread back to the key city contact to verify its technical accuracy, as well as the spirit of the effort, and encouraged corrections, additions, or any other information that related to the project that could be helpful in our telling of its story.

In the end, we feature 25 street reconfigurations that were divided into five categories:

- Bike ways

- Slow streets

- Streets for dining

- Public promenades

- The curb

In addition, we featured programs in five cities that we felt warranted a slightly longer narrative (although still quite brief) that put individual street reconfigurations into a context of a larger municipal effort. Each of these narratives were shared with city officials to ensure we were capturing their program accurately. The goal of including these narratives is to help other communities think of their street reconfiguration effort in a larger context rather than just as a series of ad hoc street design decisions. The featured cities are all larger in size (Portland, Philadelphia, Oakland, Seattle, and Paris), yet the programs they each pursued that proved helpful during the COVID emergency can be adaptable for communities of all sizes.

\subsection{DISSEMINATION OF INFORMATION}

The guidebook was distributed in digital and print form. A very limited print run was made and one print copy was distributed to every state DOT office, key contacts for each case study city, leadership of top transportation organizations (i.e. NACTO, League of American Cyclists, Association of Pedestrian and Bicycle Professionals, ITE, etc.), and to a set of key transportation researchers across the United States.

The availability of a digital download option was conducted via multiple outlets. Each person who downloaded the two previous Rethinking Streets books was 
notified by email (about 8,000), and other email and social media promotion from NITC and SCI helped spread news of the book initially.

\subsection{FINDINGS AND THE GUIDEBOOK}

\subsection{FINDINGS}

The research team looked through scores of possible case study sites using the databases being created in real time by NACTO, PBIC, and Dr. Tabitha Combs at the University of North Carolina, in addition to conducting our own online searches for possible street reconfigurations to include. Over 100 streets were investigated, and each case was categorized in a variety of ways (e.g., project type, data availability, region, permanence) and the research team looked for patterns to group these possible cases into that would be easily translatable to a range of potential stakeholders in other communities. In the end, we settled on 25 cases that represented a range of common street interventions taken across places.

The research team then worked on creating a basic template for each case study to follow so that readers of the accompanying guidebook would be able to follow a familiar, easy-to-understand, visually rich explanation of what each street-reconfiguration included. Using the previous two Rethinking Streets books as guides, key aspects for the case study template included before-and-after street images, before-and-after street cross-section diagrams, an "information bar" that shared basic street characteristics such as speed and ADT, and summary information that quickly communicated the purpose and outcomes of each street reconfiguration. Figure 2 shows an example of the street information bar and a before-and-after cross section, with yellow indicating what changed in the street and blue indicating spaces available for people to use outside of being in a vehicle (and thus in need of space to remain appropriately physically distanced).

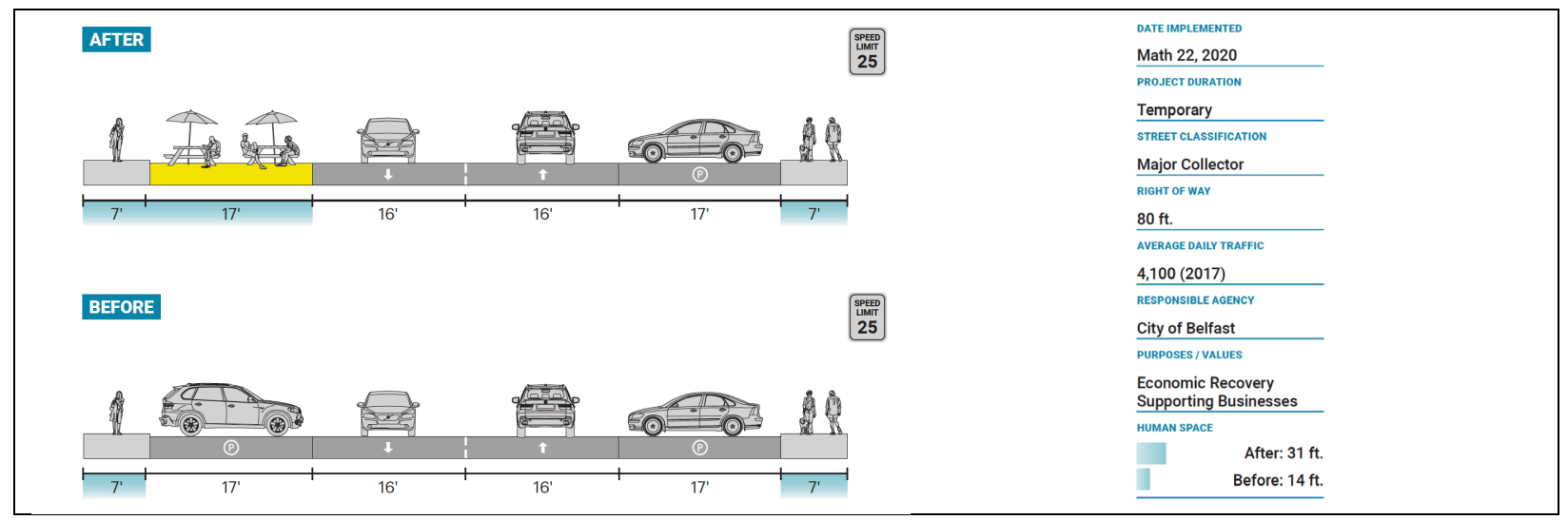

Figure 2: Example of Street Cross Section Changes and the Accompanying Information Bar 


\subsection{THE GUIDEBOOK}

The case study guidebook can be used in multiple ways. First, communities that are thinking about retrofitting some of their streets to expand their uses for physical distancing, placemaking, dining, or moving can seek out specific examples in the book that most closely resemble their project.

Second, many users will wish to see the collection of case studies in their entirety to get a full range of possibilities. Thus, users who seek out the entire collection of examples will be able to envision a whole host of opportunities within their community, given that many of the examples could be found in most communities of any size across the country.

\subsection{THE GUIDEBOOK SECTIONS}

\subsubsection{Front Matter}

The guidebook begins with a limited set of introductory subsections designed to orient users to the use of the guidebook, the impacts of COVID on transportation systems, and some probing questions about transportation in general. In the end, the guidebook's purpose is to help communities use evidence from completed projects elsewhere to better inform their own street retrofit decision making, and to do so with broad community input that can understand projects using the same base knowledge and terminology. The front matter is designed to provide this common orientation to all users throughout a community, including transportation planners and engineers, policymakers, and community stakeholders at large.

Within the front matter is a sample four-page spread of a case study street that highlights each information element on the page to point out its purpose. Each case study street is presented in the same visual format, with some information similarly included in all cases with other information customized to the unique set of circumstances being shared. The "How to Use This Guide" section orients users to the different elements they will be seeing in the remainder of the guide (see Figure 3). 

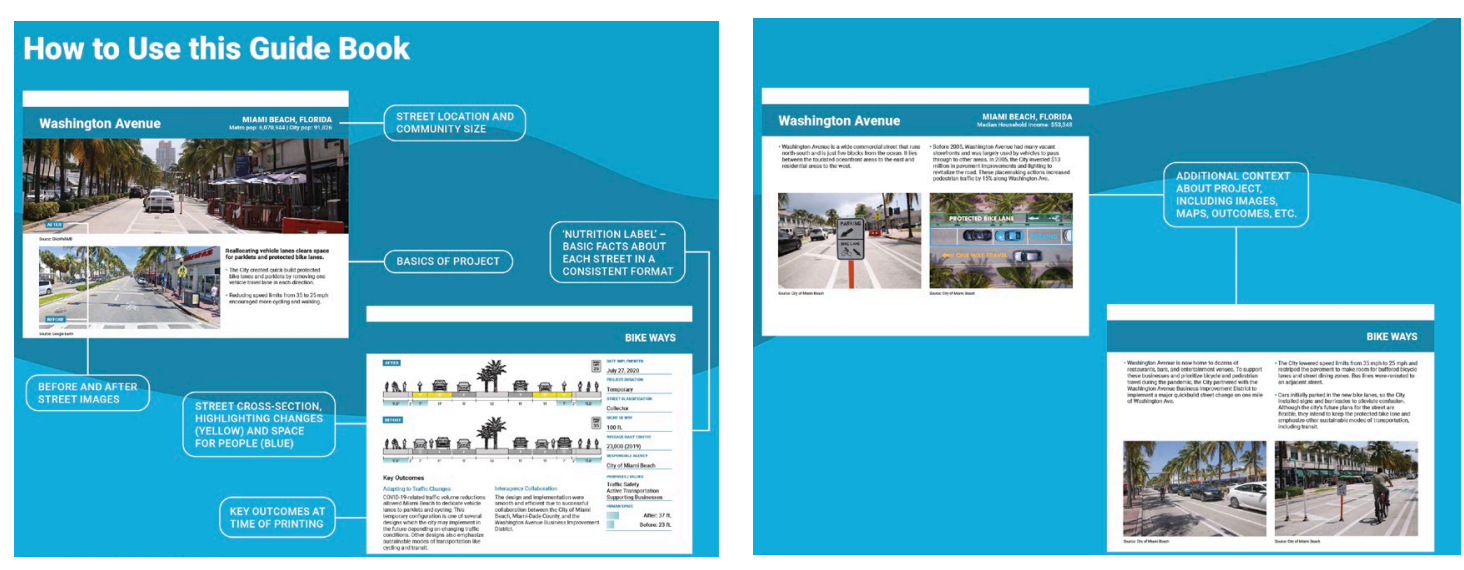

Figure 3: Sample Pages "How to Use This Guide"

\subsubsection{Guidebook Streets}

The core of the design guide is a collection of 25 completed street retrofit projects from across the U.S., presented in a consistent, visually accessible manner available to community stakeholders in communities of all sizes. Case examples are grouped into the following general bicycle facility typologies:

- Bike ways: These are streets where new dedicated cycling facilities were quickly created.

- Slow streets: These are streets where vehicular through-traffic was significantly curtailed or eliminated.

- Streets for dining: These are streets where restaurants were able to expand seating into the public right of way.

- Public promenades: These are sections of streets that were essentially converted to public plazas - places - for physically distanced gathering opportunities.

- The curb: These are examples of quick changes in curb management policy and practice to facilitate pick up and drop off.

Each open-faced page of the guidebook includes the following elements (see Figure 4 for an example):

- Location and demographics

- Before-and-after photographs and cross sections of the facility

- Key interventions and prime findings

- Photographs and additional information on the street and its context 


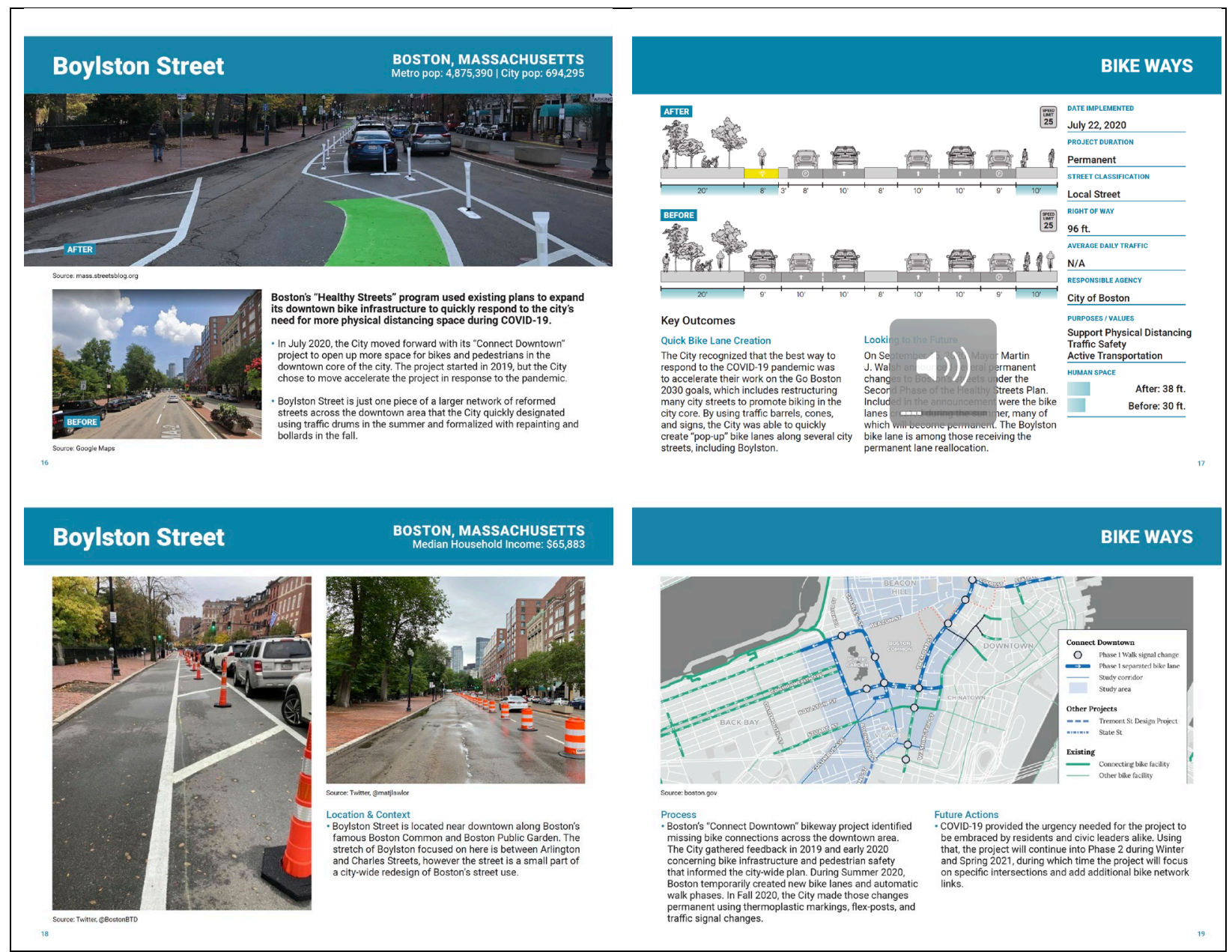

Figure 4: Sample Four-Page Case Study Spread

\subsubsection{City Program Profiles}

The guidebook also features five profiles of cities that were able to embed their quick COVID-based changes into larger, more comprehensive policies and practices. Figure 5 shows a portion of one of the guidebook's changemaker spotlight pages. The image below sows the first page of the Oakland program profile. 


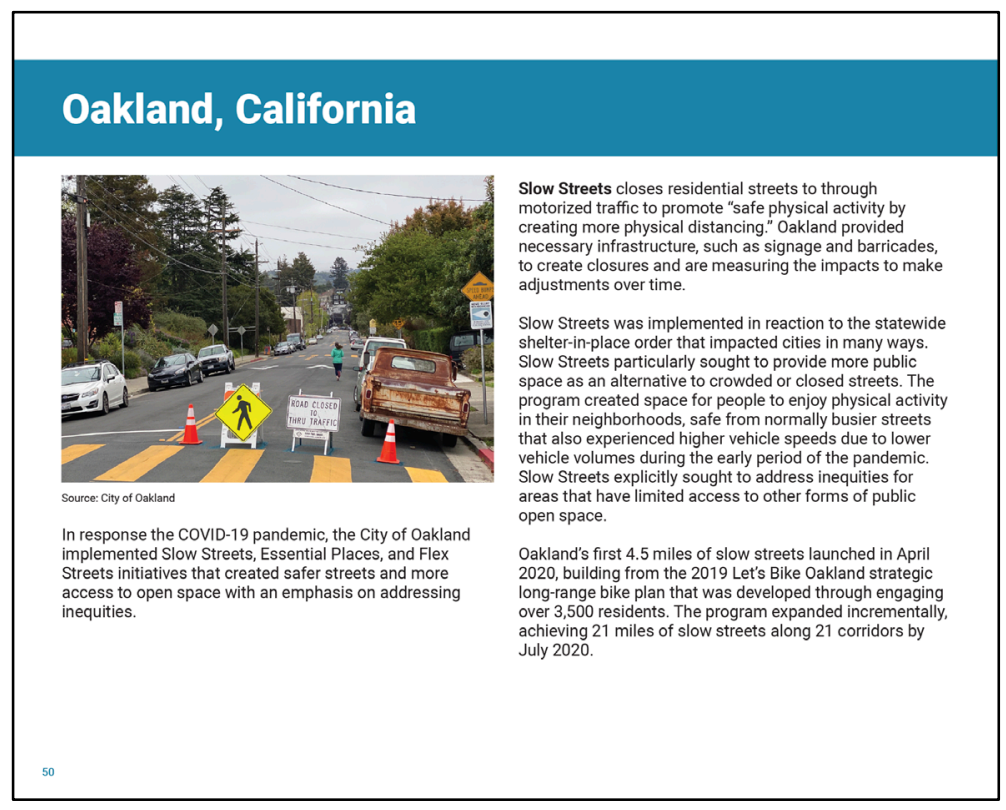

Figure 5: Example of a City Profile Page

\subsubsection{Guidebook Back Matter}

Following the presentation of street examples, citations and resources for further investigation are clearly presented. While this guidebook is designed to orient a wide variety of community stakeholders to the range of possibilities for street redesigns, it is also intended as a resource where community stakeholders can find people or projects to follow up with as necessary. The information in the back matter portion of the guide is designed to assist in this way. An example of information source references is shown in Figure 6.

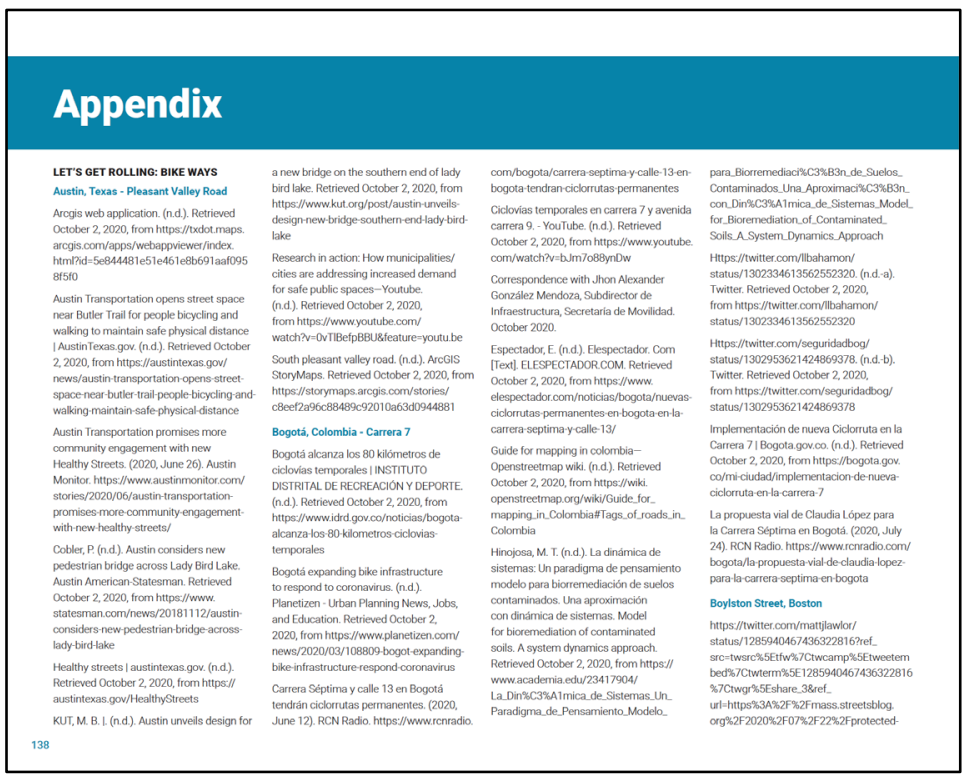

Figure 6: Sample Page of Case Study Citations 


\subsection{RECOMMENDATIONS AND CONCLUSION}

\subsection{RECOMMENDATIONS}

A few key insights became clear from the investigation of over 100 different street reconfigurations that occurred in the first few months of the COVID-19 pandemic:

1. Streets hold enormous, often untapped, potential to serve broader public purposes than they typically do.

Most space of most street right of ways in most communities primarily serve to either move or store private automobiles. Even on streets with sidewalks and bike lanes, the vast majority of public street right of way is used for private transport. What our investigation demonstrated was that that same space could be reconfigured to meet much different public priorities and that the public right of way can be better thought of as the public good it is, as opposed to the public subsidy of private transport that has been otherwise the norm.

2. Cities can act quickly to tap the public potential of the public street right of way. Reconfiguring travel or parking lanes to be used as bike lanes, bioswales, expanded sidewalks, parklets for dining or being, bike share docks, or scooter parking pods almost always are accompanied by deliberate public process and community protest that serve to delay or forego the proposed change. Naturally, city staff who put these ideas out into the public domain and supervise public input often get reluctant to push hard for these street changes when some members of the public push back hard and loud. The result is often tepid, slow-moving, process-heavy approaches to making any change to the street right of way that may reallocate space previously prioritizing the movement or storage of private automobiles to something else.

What this investigation into COVID-19-based street changes found was that cities can, in fact, act to change their streets with little to no public input and put more of the public right of way into public usage, even at the expense of space allocated to private automobiles. Given the rapid need for space to move by foot or bike or to eat or recreate in a physically distanced safe way, cities in every type of U.S. community were able to understand that they "owned" the most accessible swath of public space available to every community resident in the form of the street, and that they have the inherent power, authority, and responsibility to ensure that public space was used to meet the urgent public health, mobility, and economic needs of the community by quickly reconfiguring many streets.

3. Changes are well used, usually popular, and hold potential for more permanent rethinking of street allocations even in a post-COVID-19 environment.

In investigating the cases for this project, it became evident that the quick changes cities took were well used and popular almost immediately. Streets that were restricted against through-traffic quickly became places for kids to play or adults to socialize or move. Parking lanes that became seating for restaurants so that more customers could be served safely quickly filled up as local residents sought to support local businesses and find a change of pace from their mostly sheltered-in-place realities. Streets that completely closed to cars became vibrant public parks that allowed people to be creative in new ways. And because streets touch almost every housing unit, it was 
possible for cities to almost immediately increase the amount of public space available to all people in the community, and community members responded in kind by using the space as one would use a community park.

\section{Cities can quickly address several equity interests in revisiting how streets are} allocated and designed.

Public, open space is often distributed inequitably within urbanized areas, yet streets public spaces - reach all people where they already live, thus creating very real opportunities to expand access to public spaces everywhere. In many communities, streets have been overbuilt, particularly residential streets that often have on-street parking on both sides despite regulatory requirements for off-street parking access. These residential streets often also have enough room for three travel lanes then just over one lane is often enough for these low car-volume spaces. Many city officials, and marginalized neighborhood members, can be skeptical about reconfiguring streets that improves place-making qualities for fear of gentrifying impacts, yet by quickly and ubiquitously changing basic characteristics of street design throughout an area, such gentrifying impacts would be nullified. And during this COVID era, cities have demonstrated that quick, low-cost street changes are possible and can be done in ways quickly embraced and safely utilized by local residents - these experiences should be greatly expanded to ensure equitable access to the public spaces of streets, especially where such infrastructure has been radically overbuilt over seventy years of misguided regulatory and design standards that over-emphasized the movement and storage of private vehicles as the primary purpose of public streets.

\subsection{CONCLUSION}

Many communities across the country quickly had to make adjustments to their street designs or street reconfiguration policies to accommodate COVID-era needs of public space, eating, and movement in spatially distanced, safe ways. In many communities, pre-COVID, reallocating a parking or travel lane would often be a politically contentious issue if considered at all, yet it turns out that cities can, in fact, act quickly to rethink their public right of way. Rethinking Streets During COVID-19 is an effort to capture these quick changes, document them, and provide them back to communities across the United States as examples to draw from, whether to continue to meet COVID-era needs or to rethink streets in general for broader societal use than simply the movement and storage of private vehicles. There is a lot to be learned from cities that acted quickly, adapted, and responded to changing community needs, and perhaps the cases presented in this project can serve as evidence-based inspiration for communities of all kinds to continue to rethink their public right of way to meet a range of health, environment, equity, social, and mobility needs.

\subsection{REFERENCES}


Ahern, J. (2013). Urban landscape sustainability and resilience: the promise and challenges of integrating ecology with urban planning and design. Landscape

Ecol 28, 1203-1212.

American Public Transit Association (2020). The impact of the COVID-19 pandemic on public transit funding needs in the US. https://www.apta.com/wp-content/uploads/APTACOVID-19-Funding-Impact-2020-05-05.pdf Accessed: October 2020.

Combs, T. (2020). Local Actions to Support Walking and Cycling During Social Distancing Dataset. http://pedbikeinfo.org/resources/resources_details.cfm?id=5209

Conger, Kate (2020). "Uber and Lyft Are Searching for Lifelines." The New York Times, April 17, 2020. https://www.nytimes.com/2020/04/17/technology/uber-liftcoronavirus.html.

Dill, J., \& McNeil, N. (2016). Revisiting the four types of cyclists: findings from a national survey. Transportation research record, 2587(1), 90-99.

Gehl, J. (2013). Cities for people. Island press.

Goldbaum, Christina (2020). "Thinking of Buying a Bike? Get Ready for a Very Long Wait." New York Times, May 18, 2020.

https://www.nytimes.com/2020/05/18/nyregion/bike-shortage-coronavirus.html.

Hamidi, S., \& Ewing, R. (2015). Is sprawl affordable for Americans? Exploring the association between housing and transportation affordability and urban sprawl. Transportation Research Record, 2500(1), 75-79.

Howell, Amanda, Huijun Tan, Anne Brown, Marc Schlossberg, et al (2020). "Multilevel Impacts of Emerging Technologies on City Form and Development."

https://scholarsbank.uoregon.edu/xmlui/handle/1794/25191. Accessed: October 2020.

Le Quéré, C., Jackson, R. B., Jones, M. W., Smith, A. J., Abernethy, S., Andrew, R. M., ... \& Peters, G. P. (2020). Temporary reduction in daily global $\mathrm{CO} 2$ emissions during the COVID-19 forced confinement. Nature Climate Change, 1-7.

Maaza C. Mekuria, Peter G. Furth, and Hilary Nixon. "Low-Stress Bicycling and Network Connectivity" Mineta Transportation Institute Publications (2012).

Mehta, V. (2013). The street: a quintessential social public space. Routledge.

National Association of City Transportation Officials (2020). City Transportation Action Updates. https://docs.google.com/spreadsheets/d/1xBf6gMAwNSzNTr0CbK_uTA0ZapWGiOP58Dfn6qeC6Y/edit\#gid=1511672872 
National Association of City Transportation Officials (2018). Shared Micromobility in the U.S.: 2018. https://nacto.org/shared-micromobility-2018/.

Saelens, B. E., Sallis, J. F., \& Frank, L. D. (2003). Environmental correlates of walking and cycling: findings from the transportation, urban design, and planning literatures. Annals of behavioral medicine, 25(2), 80-91.

Schaller, B. (2018). The new automobility: Lyft, Uber and the future of American cities. http://www.schallerconsult.com/rideservices/automobility.pdf. Accessed: October, 2020.

US Environmental Protection Agency (2018). Fast Facts on Transportation Greenhouse Gas Emissions. https://www.epa.gov/greenvehicles/fast-facts-transportationgreenhouse-gas-emissions. Accessed: October, 2020. 